Amila Prasanna Sumanapala*

\title{
Macromia weerakooni sp. nov. (Odonata: Anisoptera: Macromiidae), a new dragonfly species from Sri Lanka
}

https://doi.org/10.23797/2159-6719_24_13

Received: 22 November 2020 - Accepted: 8 February 2021 - Published: 09 August 2021

\begin{abstract}
The genus Macromia is represented in Sri Lanka by two endemic species. In this paper a third presumed endemic species is described based on a single male specimen collected at Kirikitta, Weliweriya, Western Province in the low country wet zone of the country. Macromia weerakooni sp. nov. differs from its congeners in Sri Lanka by having turquoise blue eyes, an entirely black labrum, a short yellow ante-humeral stripe, an interrupted yellow stripe on the anterior margin of metepisternum and differences in the secondary genitalia and anal appendages. As this is the only record of the species knowledge of its natural history and distribution is limited. This discovery highlights the need for further systematic surveys of Odonata in Sri Lanka using sampling methods suitable for the detection of elusive species.
\end{abstract}

http://zoobank.org/References/8CCEACBE-04C3-4D2E-A69C-C034EFA6E152

Keywords: new species; endemic; South Asia

\section{Introduction}

The genus Macromia Rambur, 1842 is mainly a tropical genus distributed in Australasia, Europe and the Americas and comprises 81 species (Paulson and Schorr, 2020). In South Asia it is represented by 17 species (Kalkman et al., 2020). Out of the 14 species known from India, nine are known from the Western Ghats range (Subramanian et al., 2018), to which the Sri Lankan biodiversity has close affinities with. No Macromia species is shared between India and Sri Lanka (Kalkman et al., 2020).

Only two species of Macromia, which are both endemic, are known from Sri Lanka (Bedjanič et al., 2014; Kalkman et al., 2020). Of these two, Macromia flinti Lieftinck, 1977 is among the rarest of Sri Lankan odonates with only a single male collected in 1970 (Bedjanič et al., 2014; Lieftinck, 1977) and no confirmed subsequent records (Bedjanič et al., 2014). The other Sri Lankan representative of the genus, Macromia zeylanica Fraser, 1927 is also uncommon even though it has a wider distribution covering the low country and lower montane areas of the wet and intermediate climatic zones of the country (Bedjanič et al., 2014; Sumanapala, 2017).

In 2015, a specimen of a Macromia with injuries caused possibly as a result of colliding with a vehicle, was accidentally found by the author. It was first observed fallen on the ground beside a road, unable to fly and with an injured abdomen. The specimen was observed and photographed in life, but did not survive the injuries. After taxonomic investigations, it was recognized as a species not known to science and is described in the present paper as a new species.

\section{Materials and Methods}

The holotype was hand collected and photographed in life using a Canon EOS 1100D camera. Later the specimen was photographed using a Canon 7D Mark II fitted with a Canon EF $100 \mathrm{~mm} \mathrm{f} / 2.8 \mathrm{~L}$ Macro IS USM Lens. Secondary genitalia were photographed under an Olympus SZ51 microscope using a Canon 7D Mark II. A Spi 2000 dial verneir caliper was used to obtain measurements. Morphological terminology follows Dijkstra and Clausnitzer (2014). The distribution map was created using QGIS 2.10.1.

Abbreviations - Fw: forewing. Hw: hindwing. Ax: antenodal cross-veins. Px: postnodal cross-veins. Cux: cubital cross-veins. S1-10: abdominal segments.

* Department of Zoology and Environment Sciences, University of Colombo, Colombo, Sri Lanka; apsumanapalaAgmail.com; ORCID: 0000-0002-1482-3652 


\section{Systematic Section}

Genus Macromia Rambur, 1842

Macromia weerakooni sp. nov.

Material: Holotype - Mature male (Figure 1-5). Collected at Kirikitta, Weliweriya, Western Province, Sri Lanka (7.01955 N, 80.02976 E; Elevation 26 m) (Figures 6 \& 7). 12.iv.2015. To be deposited at the National Museum of Natural History, Colombo, Sri Lanka.

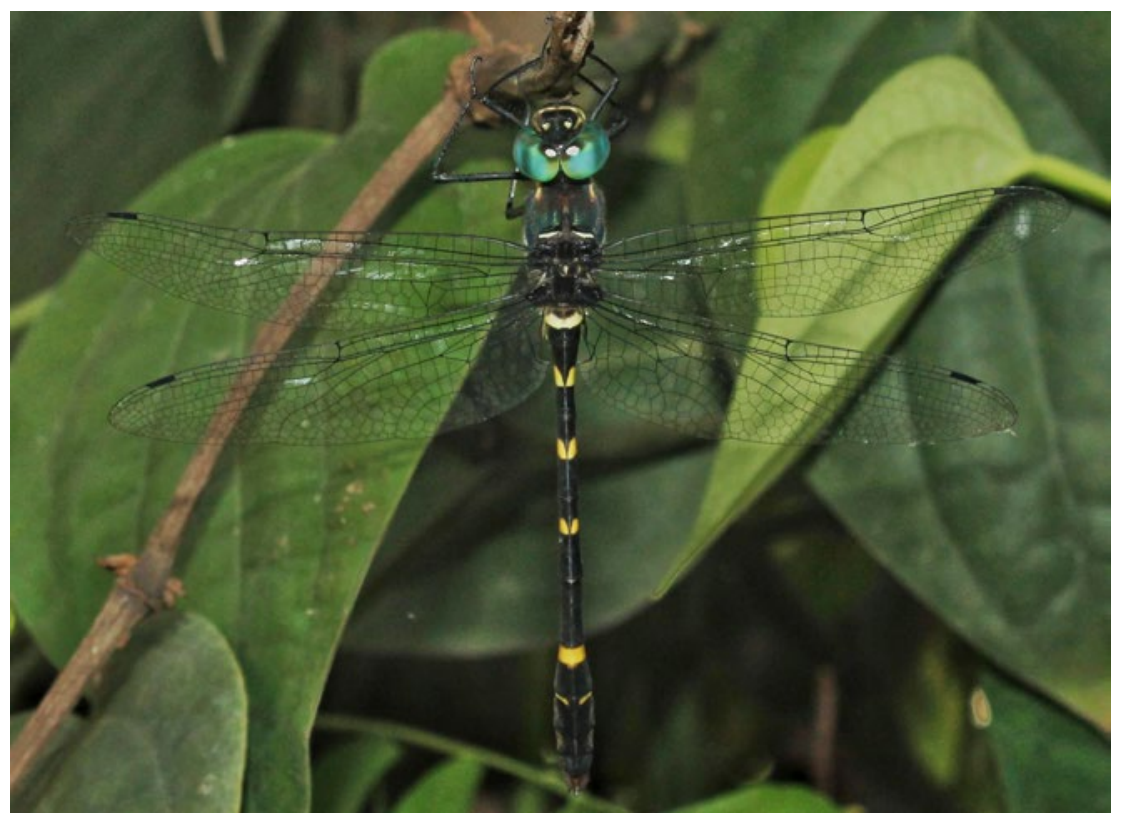

Figure 1: Macromia weerakooni sp. nov. holotype in life. Dorsal view.

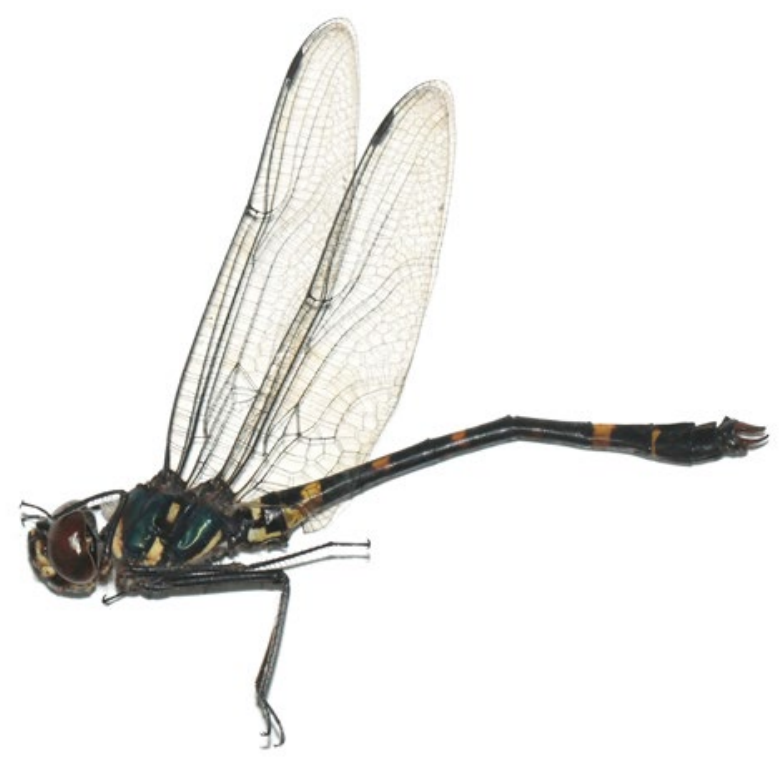

Figure 2: Macromia weerakooni sp. nov. holotype. Lateral view (Note: abdomen is broken due to an injury occurred in life). 
Referred specimens: Holotype Macromia flinti (\#75816 U. S. National Museum), collected in Uggalkaltota, Ratnapura district, Ceylon (= Sri Lanka) on 10-14 October 1970 by Oliver S. Flint Jr. Holotype Macromia zeylanica (NHMUK010208405 Natural History Museum, United Kingdom), collected from Kandy, Ceylon on 13 October 1924 by F. C. Fraser. Lectotype Macromia flavicincta (NHMUK013322958 Natural History Museum, United Kingdom). Lectotype Macromia irata Fraser, 1924 (NHMUK013322946 Natural History Museum, United Kingdom - Data Portal https://data. nhm.ac.uk/object/ef7d5ef3-b257-49bd-a9fc-99c5b7b86321). Lectotype Macromia bellicosa Fraser, 1924 (NHMUK013322948 Natural History Museum, United Kingdom - Data Portal https:/data. nhm.ac.uk/object/f5050891-02ac-4af2-beed-133c25bcdd1e).

Etymology: The specific epithet is a latinized genitive singular of Weerakoon, honouring Prof. Devaka K. Weerakoon (University of Colombo, Sri Lanka). He is an inspirational figure behind numerous biologists in the country and an academic spearheading the science based conservation activities in Sri Lanka. The author wishes to express his sincere gratitude to Prof. Weerakoon for all the guidance, support and encouragement generously provided throughout his career.

Differential diagnosis: A large, black Macromia marked with yellow, with turquoise blue eyes and a turquoise blue sheen on metalic green thorax. It can be distinguished from the two other known species of Macromia in Sri Lanka by having (1) turquoise blue eyes in adults (vs. bottle green), (2) entirely black labrum (vs. labrum with yellow markings), (3) a short citron yellow triangular antehumeral stripe that reaches less than half of the length of mid-dorsal carina (vs. long antehumeral stripe in M. zeylanica and no antehumeral stripe in M. flinti), (4) an interrupted citron yellow stripe in the anterior margin of metepisternum (vs. continuous stripe in M. zeylanica and M. flinti), (5) an upward pointed, laterally flattened short spine with a broad base on the dorsal carina of last abdominal segment (vs. a broad based slightly lower and less pointed short spine in M. zeylanica and a thin, long, backward pointed spine in M. flinti), (6) cerci having a gently outward curved pointed apex (vs. an inward curved, blunt apex in M. zeylanica and an outward curved, thin, elongated and pointed apex in M. flinti), (7) Almost entirely black tergum between the roots of the wings except for a small yellow spot between forewings (vs. prominent yellow markings across tergum in both M. zeylanica and M. flinti) and (8) differently shaped secondary genitalia. Macromia weerakooni sp. nov. is clearly distinguishable from its congeners of the genus Macromia in the Western Ghats region, India other than Macromia flavicincta Selys, 1874; Macromia irata Fraser, 1924 and Macromia bellicosa Fraser, 1924 based on the structure of the secondary genitalia. It can be distinguished from the latter three species by (1) comparatively less tapering (vs. more tapering) apex of cerci, (2) shape of the dorsal spine on S10, (3) predominantly black face with some citron yellow markings (vs. predominatly citron yellow face with less black), (4) interrupted citron yellow stripe in in the anterior margin of metepisternum (vs. continuous stripe).

Description: MALE - Head (Figures 3 A, 3 B and 4 A): Labium black in the middle with yellow lateral parts. Labrum and genae black. Anteclypeus brownish black. Postclypeus yellow with some black in the middle of the anterior margin. Short black setae present on clypeus, especially on the lateral parts. Frons glossy black with yellow markings. Antefrons with a yellow margin which extends towards the posterior margin on lateral sides as an elongated and a tapering stripe. Postfrons has two yellow spots on either side of the median ocellus. Rest of the frons glossy black. Sides of frons have black setae which extend towards the middle of the antefrons as well. Vertex glossy black and with black setae on posterior end. Occiput black. Eyes in the preserved specimen are reddish brown (turquoise blue with black spots towards the ventral side in life).

Thorax (Figures $3 \mathrm{~A}$ and $3 \mathrm{~B}$ ): Thorax dark metallic green with a turquiose blue sheen. Mesepisternum with long pale setae. Antehumeral stripe citron yellow, reaches only about half the length of the mesepisternum and triangular in shape as it tapers towards the posterior end. An interrupted citron yellow stripe along the anterior margin of metepisternum. Ventral border of metepimeron has a narrow citron yellow stripe. Legs long and black with yellow on the posterior side of coxa and trochanter.

Wings (Figure 5): Clear. Venation black. Right Fw with $13 \mathrm{Ax}$ and 7 Px while the left Fw has $15 \mathrm{Ax}$ and 7 Px. Right Hw with $10 \mathrm{Ax}$ and $10 \mathrm{Px}$ and left with $11 \mathrm{Ax}$ and 10 Px. Pterostigma elongated, black and covers two cells. 6 Cux in Fw and 4 in Hw. Sectors of arculus fused at base in Hw but not fused at the base in Fw. Supertriangle has $4 \mathrm{Cux}$ in right $\mathrm{Fw}$ and 3 in left Fw. Hw supertriangle has $2 \mathrm{Cux}$. Anal loop with 8 cells. Triangle without cross-veins. Discoidal field of both Fw and Hw has 2 cells at base and at the wing margin right $\mathrm{Fw}$ and left $\mathrm{Fw}$ has 12 and 10 cells respectively, while $\mathrm{Hw}$ has 13 cells. 


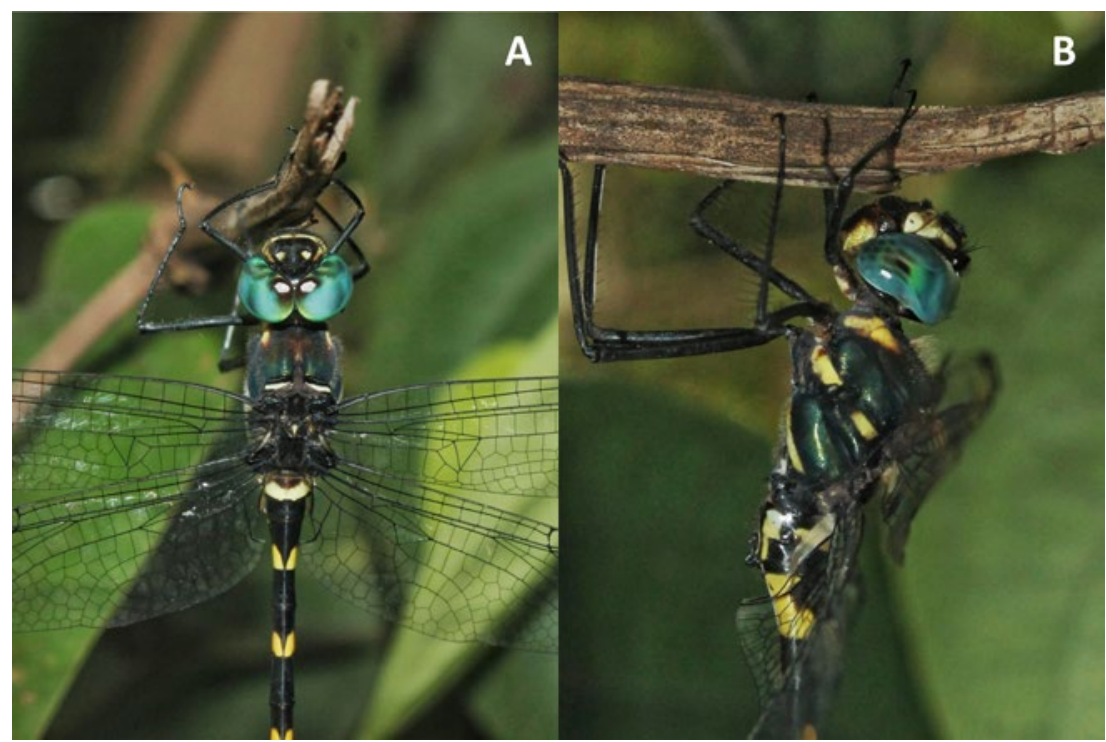

Figure 3: Macromia weerakooni sp. nov. holotype in life. Dorsal (A) and lateral (B) view of head and thorax.

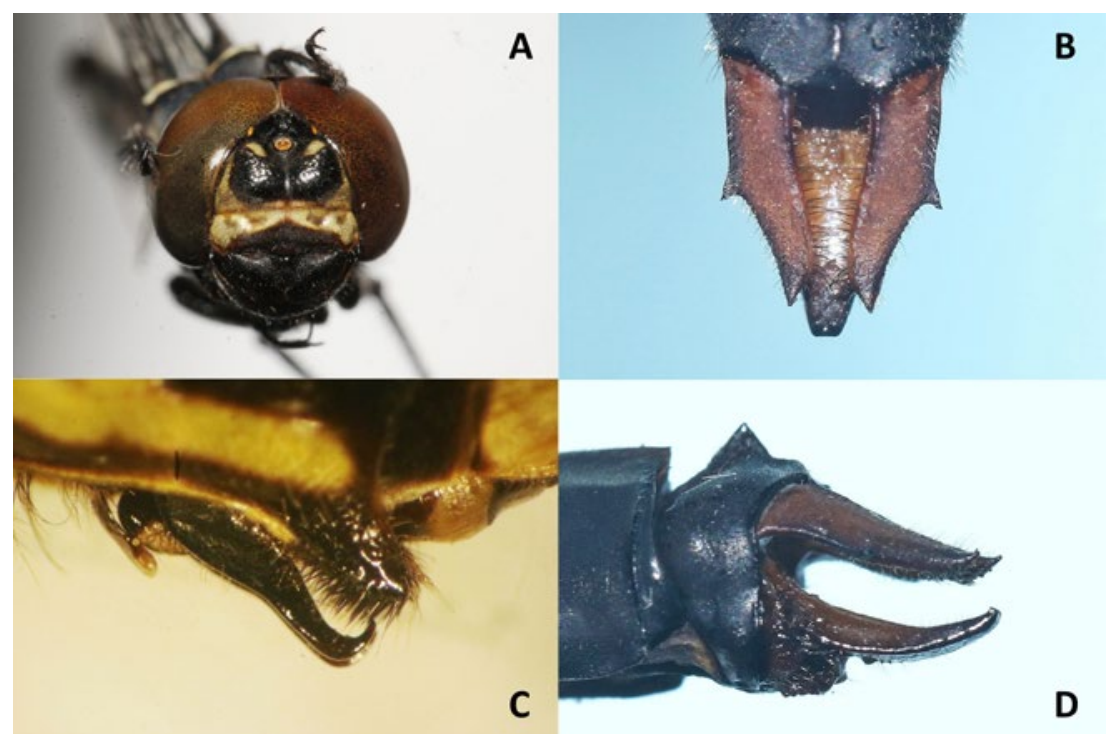

Figure 4: Macromia weerakooni sp. nov. holotype. Frontal view of head (A); dorsal view of cerci and epiproct (B); lateral view of secondary genitalia (C); lateral view of S10, cerci and epirpoct (D).

Abdomen (Figures 1 \& 2): Black and marked in citron yellow. S1 fully black. S2 with a dorso-lateral pale yellow mark and lateral yellow spot towards the ventral side on its anterior half. A thin pale yellow stripe extends from the anterior ventral yellow spot and runs along the ventral border for about two thirds of the posterior half. S3 has a yellow mark covering the ventral portion of anterior half and broadens towards the dorsal carina from either side from the middle of the segment towards its posterior end. These yellow patches are separated by a thin black wedge shaped area along the dorsal carina. S4 and S5 with two narrowly divided dorsolateral yellow spots in the anterior half. S6 fully black. S7 with a broad yellow basal ring that covers about one third of the length. S8 has a thin incomplete yellow ring, starting from below, running on either side along the basal margin and ending with a slightly posteriorly curved, club shaped blunt tip. In between these narrow basal yellow portions, dorsum of S8 black. S9 and S10 fully black. An upward pointed dorsal spine with a broad base on the last segment. Short black setae on the lateral sides of the posterior half of S10. 


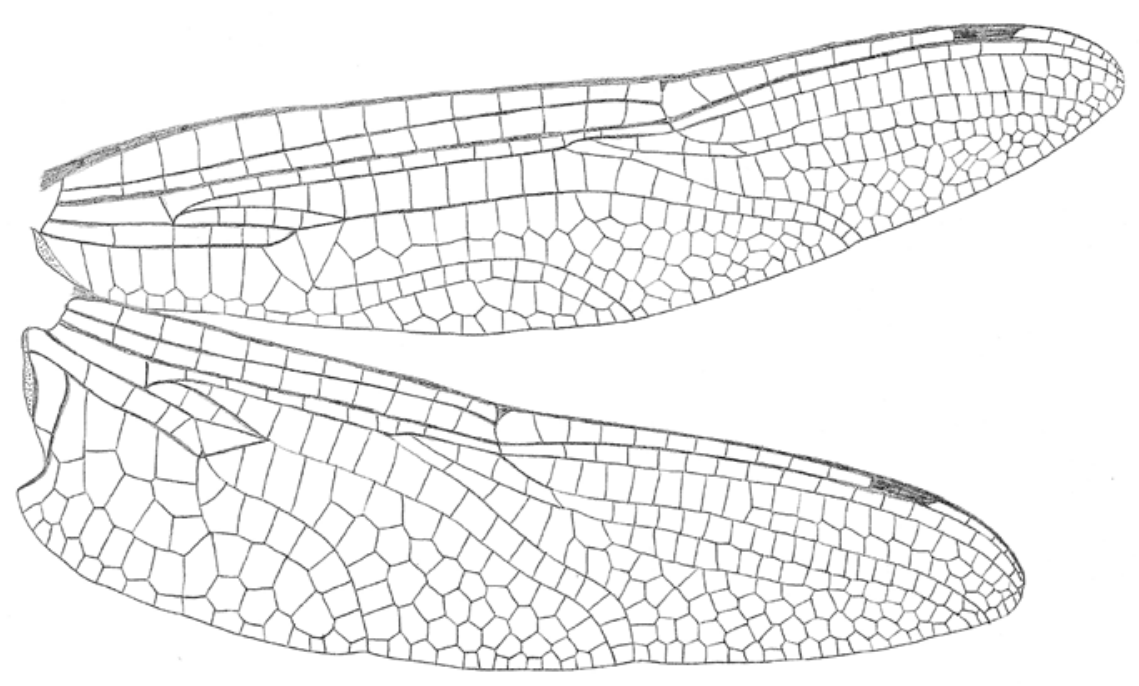

Figure 5: Macromia weerakooni sp. nov. holotype. Line drawing of right Fw and Hw.

Appendages (Figures 4 B \& 4 D) dark reddish brown. The cerci about 1.5 times the length of S10, broad at the base and taper towards the apex to end in an outward directed spine. Inner margin of the cerci curved in the posterior half to form the spine in the posterior end. A posteriorly angled lateral spine on the outer margin of each cerci. A row of very small teeth on the ventral surface of cerci posterior to the lateral spine. The epiproct slightly longer than the cerci and curved upward in the posterior half. Two minute and upward pointed notches on the epiproct tip. Setae on cerci, especially in the apical halves.

Secondary genitalia (Figure $4 \mathrm{C}$ ): Anterior lamina stalk-like, elongated and protuberant. Reaches a little less than a half of the length of the hamule. Hamule witha broad lobe and tapers towards the apex curving upward to end with a well defined upward hook. Genital lobe has a blunt, downward directed apex and covered with black setae.

Measurements (mm): Abdomen with appendages - 47.8, Forewing - 43.2, Hindwing - 41.1, Cerci 2.3, Epiproct - 2.7.

\section{Female - Unknown.}

Habitat: The holotype was collected on a road running through a paddy field in a semiurban area. The irrigation canals with riparian vegetation running through or at the margin of the paddy fields are the closest potential habitat of the species in its type locality.

Distribution: The type locality (Figure 6) is located in the low country wet zone of Sri Lanka. No other locality records are known thus far.

Natural History: Since the holotype was collected in April it is likely that the adults are on the wings during the southwestern monsoon season. No other information is known of the natural history of the species. However, it can be assumed that the natural history of Macromia weerakooni $\mathrm{sp}$. nov. is generally similar to that of other Macromia species in the region.

Vernacular Name: The English vernacular name suggested for the species is "Sri Lankan Turquoise blue Cruiser" based on the turquoise colour of the eyes. 


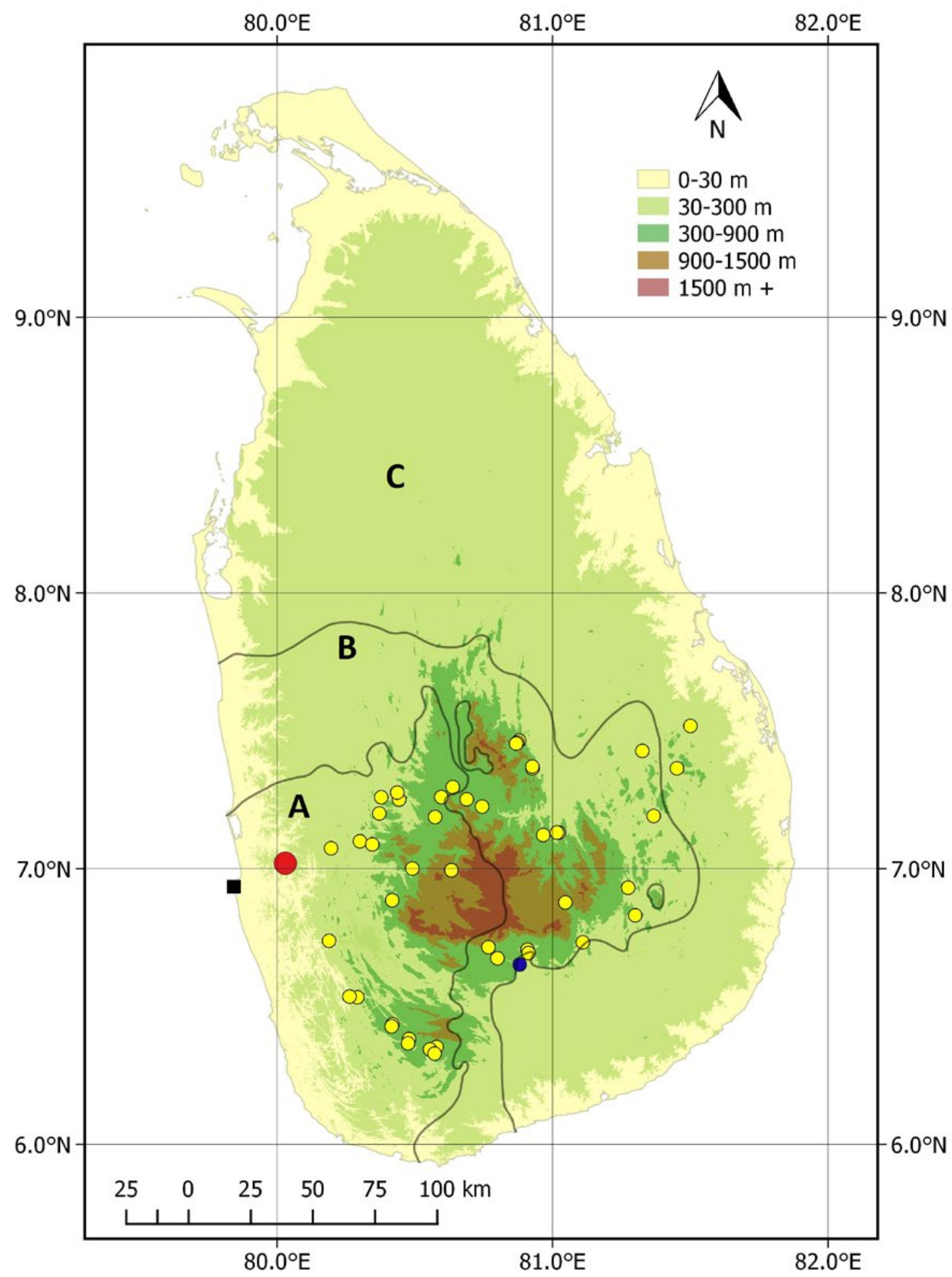

Figure 6: Type locality of Macromia weerakooni sp. nov. (red circle) and known distribution of M. zeylanica (yellow circles: after Bedjanič et al. 2014 and author's unpublished data), M. flinti (blue circle) and the location of Colombo, the capital city of Sri Lanka (black square). A - wet zone, B - intermediate zone, and C - dry zone. 


\section{Discussion}

With the discovery of Macromia weerakooni sp. nov., the genus Macromia is represented in Sri Lanka by three species. The new species is easily distinguishable from its congeners in Sri Lanka, M. zeylanica (Figure 8) and M. flinti, by the differences in the eye colour, facial and thoracic markings and the structure of anal appendages and secondary genitalia. It is also larger than M. zeylanica (Fraser, 1927; Lieftinck, 1977). Among the other Macromia found in the South Asian region, $M$. weerakooni is distinct from all but M. flavincicta, M. bellicosa and M. irata based on the structure of secondary genitalia (Fraser, 1924, 1936). It can be distinguished from the latter three species based on the structures of anal appendages, dorsal spine on abdominal segment 10, facial markings and interrupted lateral thoracic stripe. In the field, especially in flight, $M$. weerakooni might be mistaken for the comparatively larger Epophthalmia vittata cyanocephala Hagen, 1867, which also has bluish eyes and a dark body marked in yellow (Bedjanič et al., 2014; Sumanapala, 2017). However, $M$. weerakooni's smaller size, short antehumeral stripe and abdomen marked only in yellow with no reddish orange markings towards the posterior half, will separate it from E. vittata.

Since Macromia weerakooni is only known from Sri Lanka it can be considered a species endemic to the country. The type locality is in the northern part of the biodiversity rich, wet climatic zone of the country. However, the habitats present at the type locality and its geo-climatic conditions are not unique or geographically restricted. Therefore it is unlikely that the species is restricted to this specific area. Of the other known Macromia species of Sri Lanka, M. zeylanica has a relatively wide distribution (Figure 5) and occupies a range of lotic habitats with riparian vegetation, some of which are present, also at the type locality of $M$. weerakooni. It is likely that $M$. weerakooni also occurs in similar habitats and has a wider distribution in the low country wet zone of the country. The absence of additional records of the species may be due to low abundance, elusive habits, short flight season or limitations in sampling.

Since the species is only known from a single specimen collected from a single locality, its exact range, habitat preferences, adult flight phenology, larval stages and other biological or ecological information is currently unavailable, making Macromia weerakooni one of the priority endemic species for further research. Documentation of additional records and observations on natural history are important for a better understanding of the species and for ensuring its conservation.

The fact that this new species was discovered in a semiurban environment (Figure 7) not far from the densely populated capital city of Sri Lanka, Colombo (Figure 6), highlights several interesting possibilities. It suggests that there may be other elusive species of Odonata even among large anisopterans in Sri Lanka yet unknown to science, and that they may occupy habitats outside the protected areas and even occur in densely populated, human dominated landscapes as well. This calls attention to the need for further surveys covering a broad range of habitats with suitable sampling methods to detect less abundant, elusive and crepuscular species in order to document and understand the odonate fauna of the country. The discovery of $M$. weerakooni also serves to emphasize the importance of conserving the remaining habitats in urban and semiurban landscapes to support the local biodiversity. 


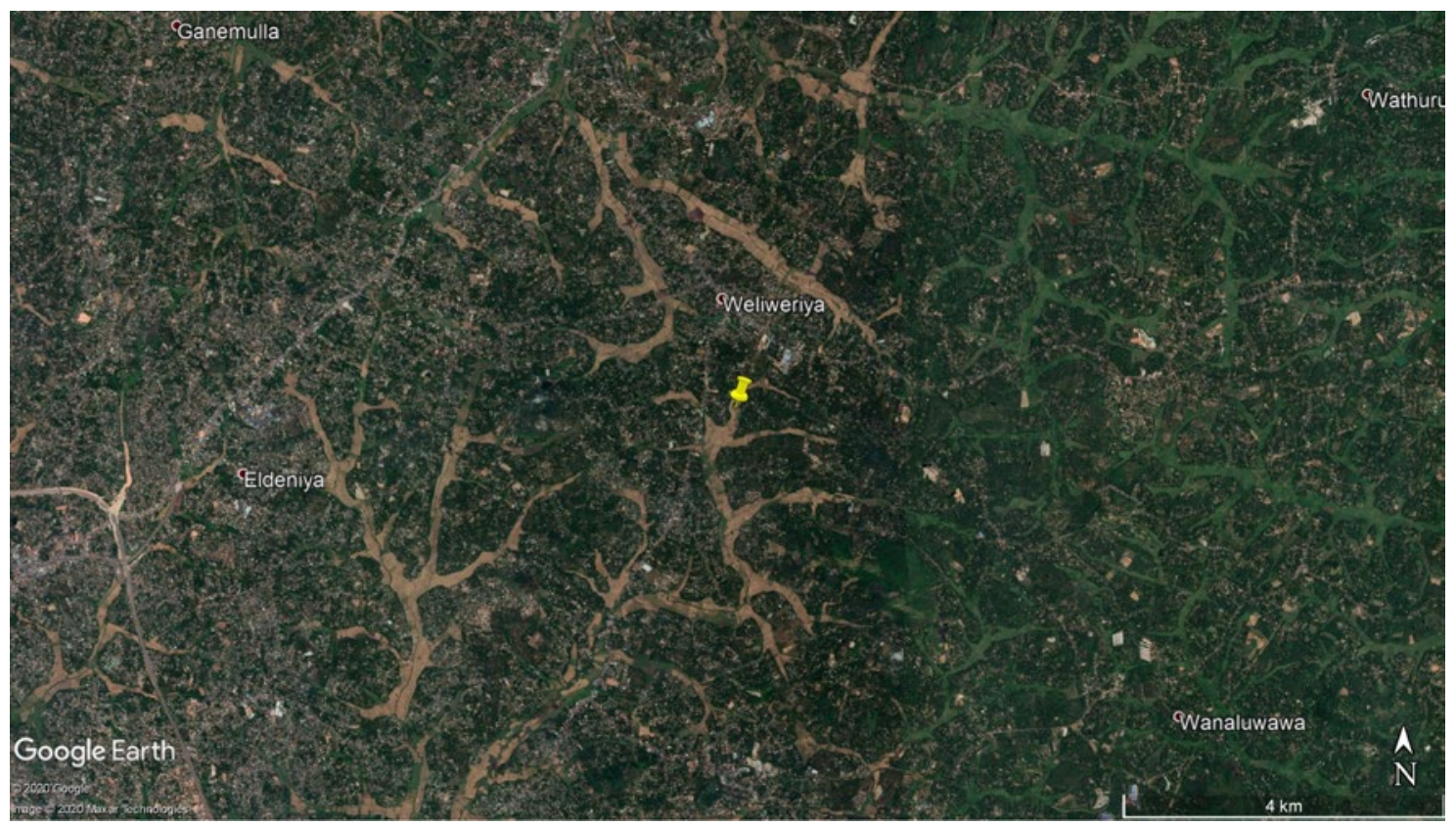

Figure 7: Google Earth image of the type locality (yellow pin) and surrounding area dominated by human modified landscapes.

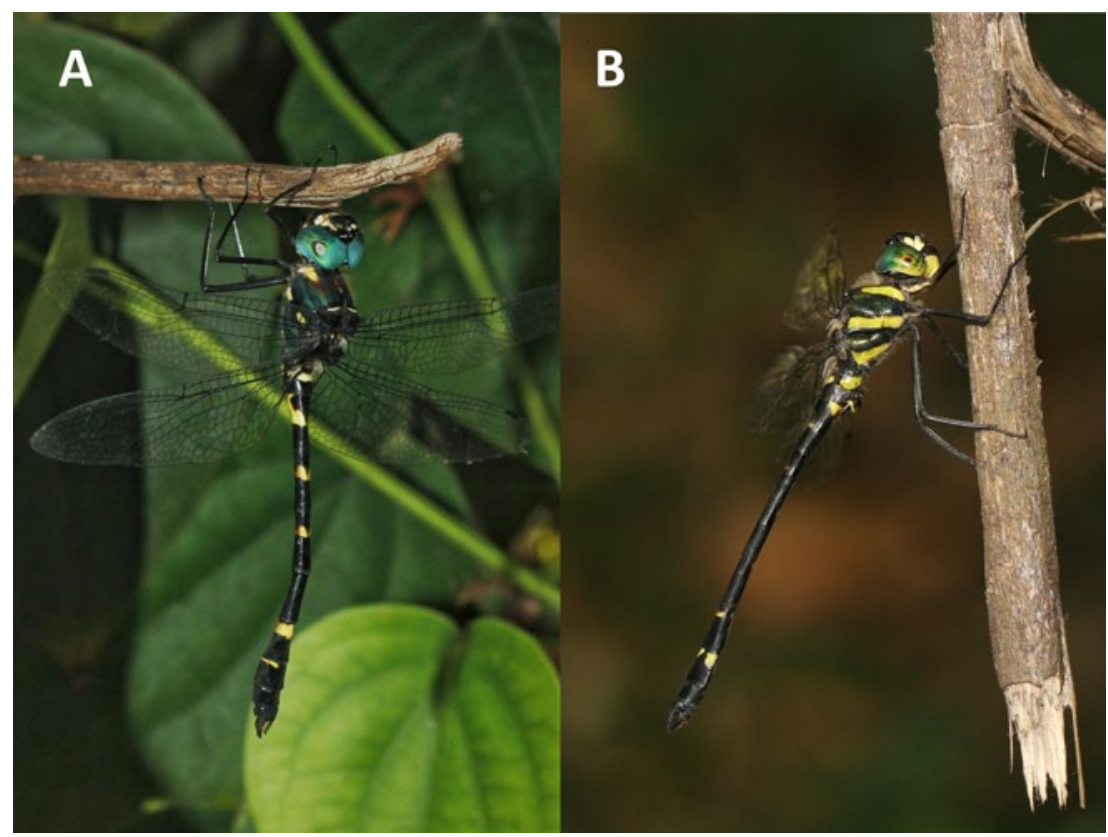

Figure 8: A comparison between males of Macromia weerakooni sp. nov. (A) and Macromia zeylanica (B) in life. 


\section{Acknowledgement}

The author expresses his gratitude to Ben Price of the Natural History Museum of London and Karolyn Darrow and Oliver Flint of U. S. National Museum for providing photographs of the specimen referred. Department of Wildlife Conservation, Sri Lanka is thanked for the permit for further surveys (WL/3/2/91/15). Dilani Sumanapala and Priyantha Wijesinghe are thanked for their invaluable support and inputs in improving the manuscript. The reviewers of the manuscript are thanked for the constructive reviews provided. Kalya Subasinghe, Divanka Randula and Muditha Katuwawala are thanked for their support and encouragement.

\section{References}

Bedjanič, M., van der Poorten, N., Conniff, K. \& Šalamun, A. (2014). Dragonfly Fauna of Sri Lanka: distribution and biology with threat status of its endemics. Pensoft.

Dijkstra, K. D. B. \& Clausnitzer, V. (2014). The Dragonflies and Damselflies of Eastern Africa. Handbook for all Odonata from Sudan to Zimbabwe. Studies in Afrotropical Zoology, 298. Tervuren: Royal Museum for Cenral Africa.

Fraser, F. C. (1924). A survey of the odonate (dragonfly) fauna of western India with special remarks on the genera Macromia and idionyx and descriptions of thirty new species. Records of the Indian Museum, 26(5), 423-522.

Fraser, F. C. (1927). Description of twenty new Indian dragonflies. Records of the Indian Museum, 29(2), 63-90.

Fraser, F. C. (1936). The Fauna of British India including Ceylon and Burma: Odota Vol. III. Tailor and Francis.

Kalkman, V. J., Babu. R., Bedjanič, M., Conniff, K., Gyeltshen, T., Khan, M. K., Subramanian, K. A., Zia, A., \& Orr, A. G. (2020). Checklist of the dragonflies and damselflies (Insecta: Odonata) of Bangladesh, Bhutan, India, Nepal, Pakistan and Sri Lanka. Zootaxa, 4849(1), 001-084. https:// doi.org/10.11646/zootaxa.4849.1.1

Lieftinck, M. A. (1977). New and little known Corduliidae (Odonata: Anisoptera) from Indo-Pacific Region. Oriental Insects, 11(2), 157-179.

Paulson, D. \& Schorr, M. (2020). World Odonata List. University of Puget Sound. Accessed on 21.11.2020.

Subramanian, K. A., Emiliyamma, K. G., Babu, R., Radhakrishnan, C. \& Talmale, S. S. (2018). Atlas of Odonata (Insecta) of the Western Ghats. Zoological Survey of India.

Sumanapala, A. P. (2017). A Field Guide to the Dragonflies and Damselflies of Sri Lanka. Ceylon Tea Services PLC. 